\title{
Effects of Nursing Home Residency on Diabetes Care in Individuals with Dementia: An Explorative Analysis Based on German Claims Data
}

\author{
Larissa Schwarzkopf Rolf Holle Michaela Schunk \\ Helmholtz Zentrum München, German Research Center for Environmental Health (GmbH), \\ Institute of Health Economics and Health Care Management, Neuherberg, Germany
}

Keywords
Care processes $\cdot$ Cost of illness $\cdot$ Institutional care $\cdot$ Home care $\cdot$ Administrative data .
Germany

Abstract

Aims: This claims data-based study compares the intensity of diabetes care in community dwellers and nursing home residents with dementia. Methods: Delivery of diabetes-related medical examinations (DRMEs) was compared via logistic regression in 1,604 community dwellers and 1,010 nursing home residents with dementia. The intra-individual effect of nursing home transfer was evaluated within mixed models. Results: Delivery of DRMEs decreases with increasing care dependency, with more community-living individuals receiving DRMEs. Moreover, DRME provision decreases after nursing home transfer. Conclusion: Dementia patients receive fewer DRMEs than recommended, especially in cases of higher care dependency and particularly in nursing homes. This suggests lacking awareness regarding the specific challenges of combined diabetes and dementia care.

(C) 2017 The Author(s)

Published by S. Karger AG, Basel

\section{Introduction}

In the context of demographic aging, the disease spectrum is shifting toward chronic conditions. Among others, diabetes mellitus type 2 (diabetes) and dementia are 2 prominent illnesses with an age-associated risk of incidence. For Germany, the prevalence of dementia in individuals aged $\geq 65$ years is estimated at about $7 \%$, corresponding to about 1.3 million 
patients $[1,2]$. Regarding diabetes, around $20 \%$ in the age group $\geq 65$ years are thought to be affected $[3,4]$.

There is growing evidence that somatic comorbidity in individuals with dementia is not treated with the same emphasis as in cognitively unimpaired elderly [5-7]. Among several comorbid conditions, diabetes plays a prominent role for several reasons: first, individuals with diabetes seem to have a higher risk of developing dementia [8]; second, current approaches in diabetes management rely strongly on the patient's personal initiative, but the required ability to participate actively is lost step by step in the course of dementia. In consequence, dementia patients need family-based and professional support to successfully handle diabetes. Especially for informal caregivers, looking after diabetes-related aspects on top further acerbates strain [9-11]. Hence, they might be more prone to excessive demands in the context of combined diabetes and dementia than professional caregivers. It can therefore be assumed that the intensity of diabetes care improves with increasing participation of professional nursing staff.

Recently, the topic of diabetes care in individuals with dementia has gained scientific interest, but research has focused on differences between individuals with and without dementia [12-14]. There is also some evidence on the status of diabetes care in various residential settings [15-17]. However, differences in diabetes care between community dwellers and nursing home residents with dementia have been sparsely investigated [18]. Moreover, previous research disregarded costs of care, but only a combined look at service delivery and financial requirements results in sound conclusions, where redesigning current care structures has high potential to improve quality and efficiency.

Against this background, our claims data-based study aims to (1) compare diabetesrelated medical examinations (DRMEs) in community dwellers and nursing home residents with dementia, (2) describe the effect of nursing home transfer on the provision of DRMEs, and (3) evaluate diabetes-related costs of care in the community and the nursing home setting.

\section{Subjects and Methods}

\section{Sample Selection}

All analyses refer to a dataset provided by the AOK Bavaria Statutory Health Insurance (SHI) Fund for a previous analysis, which includes 12,040 individuals with dementia born before 1941 and continuously enrolled during 2005 and 2006. For further details see Schwarzkopf et al. [19].

Data analyses were conducted according to national data protection laws, and AOK Bavaria approved the use of their data for the following analyses. We conducted a retrospective analysis of completely anonymized claims data which - according to a self-disclosure of the ethics committees of the Bavarian State Medical Association - does categorically not require explicit ethics approval.

For the following analyses looking at health care service utilization and costs in 2006, we first selected individuals with prevalent dementia by including all insurants with in- or outpatient diagnoses of dementia (ICD-10 codes F00, F01, F02, F03, G30) or prescriptions for specific anti-dementia drugs (cholinesterase inhibitors [ATC code N06DA] or memantine [ATC code N06DX01]) in at least 3 out of 4 quarters in 2005. These criteria applied to 7,529 individuals. Then, we identified the subpopulation with diabetes based on the criteria of Hauner et al. [4], which reflect (a) a minimum of 3 diabetes diagnoses (ICD-10 codes E10E14) within 3 quarters of 2005, (b) a minimum of 2 prescriptions for antidiabetic drugs (ATC code A10A [insulin] or A10B [OAD]) in 2005, or (c) a prescription for antidiabetic drugs 


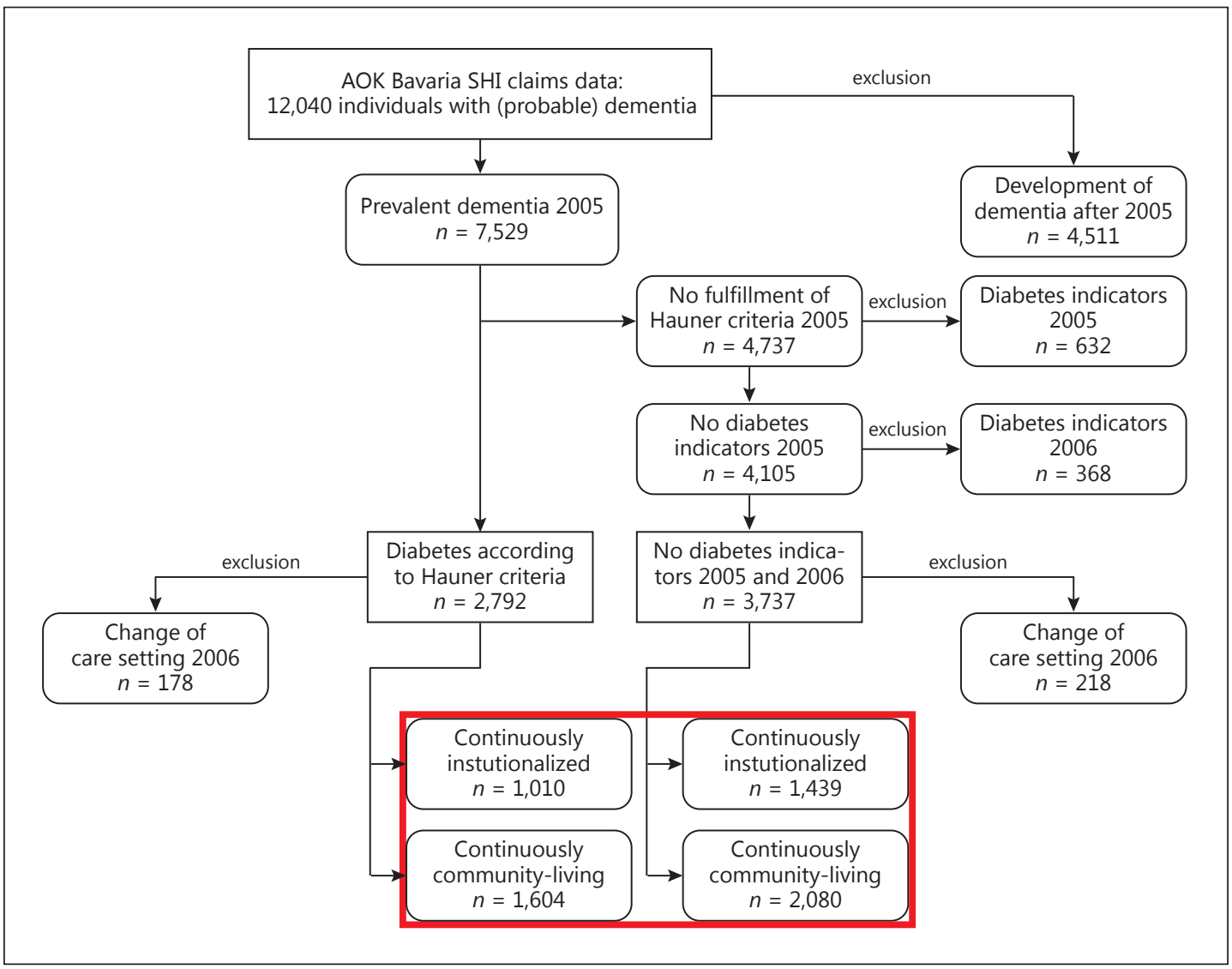

Fig. 1. Sample selection process. SHI, Statutory Health Insurance.

combined with a diagnosis of diabetes and a documented measure of blood glucose or glycated hemoglobin (HbA1c) in 2005. A total of 2,792 individuals with dementia were classified as having diabetes.

A control population with dementia but without diabetes was created by taking the remaining dementia patients $(n=4,737)$ and excluding all individuals who received any diabetes diagnoses or any antidiabetic drug prescriptions during 2005 and 2006. This sample $(n=3,737)$ was needed to run the excess cost analyses.

Finally, individuals with and without diabetes were allocated to the community and the nursing home/institutional sector (for details see "Assessment of Care Arrangement"), ending up with 1,604 community dwellers and 1,010 nursing home residents with diabetes as well as 2,080 community dwellers and 1,439 nursing home residents without diabetes. For details on sample selection see Figure 1.

\section{Assessment of Care Arrangement}

The term "care arrangement" describes the combination of "type of benefit" and "level of care dependency" (LoCD). Corresponding information was assessed based on data from compulsory long-term care insurance (LTCI), designed as partial financial support for all SHI insurants who are considered to be in need of care as per the Code of Social Law. In this context, need for care is defined as restricted capacities in (instrumental) activities of daily living ([I]ADL). 
Briefly, LTCI distinguishes 4 different types of benefit reflecting an increasing degree of professionalization in care provision: (a) "transfer payments for informal caregivers," (b) "combined informal and professional care," (c) "professional ambulatory care," and (d) "institutional care." Concepts (a) to (c) belong to the community setting and (d) to the institutional setting. Independent of the type of benefit, LTCI beneficiaries are grouped into 3 LoCD reflecting the degree of (I)ADL impairment. Each of the 3 LoCD is connected to a fixed setting-specific monthly tariff. LoCD1 (mildly dependent) requires a minimum of $90 \mathrm{~min}$ (I) ADL support per day. LoCD2 (moderately dependent) requires a minimum of 180 min support per day. LoCD3 (severely dependent) requires a minimum of 300 min support per day. The assignment to a distinct LoCD is based on an examination by the SHI's medical review board, whereas the choice of the type of benefit is up to the LTCI beneficiaries themselves. A detailed description of the German SHI system is provided elsewhere [20,21]. LoCD can change at any point of time; thus, we set the LoCD documented for June 30 as the point of reference for our analyses.

To reflect the residential setting, we differentiated between community-based and institutional (i.e., nursing home-based) care. The entire 2006 information on type of benefit was taken into account to classify (a) individuals with an uninterrupted sequence of "institutional care" as nursing home residents, (b) individuals with "institutional care" starting in 2006 as admissions to nursing homes, and (c) individuals without documentation of "institutional care" and those without LoCD as community-living.

\section{Outcome Parameters}

Diabetes-Related Medical Examinations. The intensity of diabetes care was approximated via essential DRMEs, namely control of (a) blood glucose, (b) HbA1c, (c) microalbumin, (d) creatinine, and (e) cholesterol levels as well as (f) examination of the ocular background. We identified these 6 DRMEs via their item codes in the schedule of fees and checked whether they had been performed at least once per year as recommended within the guidelines [22] and specific recommendations on diabetes care in the elderly.

Costs of Diabetes Care. The costs of diabetes care were assessed using an excess cost approach [23], which compares individuals with and without diabetes. The difference in spending is assumed to be diabetes-related. Inpatient treatment, outpatient treatment (general practitioners and medical specialists), medication, nonphysician services, medical aids, home health care (i.e., short-term medical nursing), and rehabilitation were considered. The amount dispensed on the distinct service categories is documented directly in the claims data. As hospital care and rehabilitation do not refer to a distinct point in time but to a defined period, utilization of corresponding services might have started before and ended after 2006. To more precisely assess costs incurred during the observation period, we distributed service utilization to the distinct years whenever treatment only partly took place in 2006 . Then, the entire expenditures for the treatment episode were assigned proportionally to the distinct phases, implying constant amounts per day.

\section{Statistical Analysis}

All analyses were performed with SAS 9.3 and refer to 2006 data unless reported otherwise.

Diabetes-Related Medical Examinations. To analyze differences regarding the intensity of diabetes care, we assessed the percentage of community dwellers and nursing home residents with at least 1 documented code for each DRME. Based on odds ratios and descriptive $p$ values, the groups were compared via logistic regression models adjusted for age (in years), gender, type of diabetic medication, LoCD, and comorbidity. Diabetic medication distinguished "nonpharmacological therapy," "insulin only," "oral antidiabetic drugs (OADs) only," and 
"combination of insulin and OADs." Patients were assigned to one of these groups if they had received at least 1 corresponding prescription. The comorbid conditions hypertension (ICD-10 codes I10-I14), chronic ischemic heart disease (ICD-10 codes I20, I21, I25), congestive heart failure (ICD-10 code I50), cerebrovascular event (ICD-10 codes G45, I60-I64, I69), and hyperlipidemia (ICD-10 code E78) were considered in a dummy-coded format. Conditions were chosen according to the suggestions of Du et al. [24] using the coding algorithm of Schäfer et al. [25]. As analyses by covariate interaction indicated an additional setting-related effect of (I)ADL dependency, we ran all analyses stratified by LoCD. The longitudinal effect of nursing home placement was investigated by looking at those 149 individuals who moved to a nursing home in 2006 and survived from the date of admission for at least 1 year. Here, changes in DRME provision within the 365 days before and following the date of nursing home placement were explored within mixed models to account for intra-subject correlation [26]. The analyses were adjusted for age, gender, comorbidity, and LoCD on the date of admission.

Costs of Diabetes Care. Using individuals with dementia but without diabetes as the reference category for each setting, we calculated diabetes-related expenditures for community dwellers and nursing home residents with dementia for the distinct LoCD strata. Regarding service categories, where $\geq 90 \%$ of individuals incurred any costs, we applied 1-part generalized linear gamma models to assess excess costs. Gamma models account for the right-skewed distribution of cost data but are only defined for positive values [27]. Thus, we assigned the fictive value of EUR 10 to individuals without costs to avoid their exclusion from the analyses. This approach was used for "total SHI expenditures," "general practitioners' treatment," and "medication." For the categories "medical specialists' treatment," "hospital care," "nonphysician services," "medical aids," "home health care," and "rehabilitation," we applied 2-part models. In the first part, the probability of service use is calculated based on logistic regression. In the second part, costs per service user are calculated for individuals with positive probability via a gamma model [28]. To derive costs per capita, probability of use and costs per user are combined. For both 1- and 2-part models, costs and cost differences were calculated via recycled predictions using setting as the coefficient of interest [29]. The cost models accounted for the covariates diabetes (yes/no), age (in years), gender, comorbidity, and a diabetes $\times$ setting interaction. As the covariate profile varied to some extent between the LoCD strata, we set strata-specific figures on the average figures observed in the entire sample to enable a sound comparison of diabetes-related costs across the different strata.

\section{Results}

\section{Baseline Characteristics}

Nursing home residents with dementia and diabetes were about 4 years older than their community-living counterparts, more likely female, and assigned to a higher LoCD (Table 1). Comorbid conditions related to metabolic syndrome were diagnosed more frequently among community dwellers, whereas a history of cerebrovascular events and congestive heart failure was more common in nursing home residents. There were slight differences regarding diabetic medication, with higher prescription rates for OADs in the community and for insulin in the institutional sector but, irrespective of care setting, the biggest subgroup was that without pharmacological treatment of diabetes.

\section{Diabetes-Related Medical Examinations}

In both settings, DRMEs took place at quite a low level. The 6 corresponding prevalence rates were even lower in nursing homes than in the community setting, with the difference 
Table 1. Baseline characteristics of individuals with dementia and diabetes

\begin{tabular}{|c|c|c|}
\hline & $\begin{array}{l}\text { Nursing home } \\
\text { residency } \\
(n=1,010)\end{array}$ & $\begin{array}{l}\text { Community- } \\
\text { living } \\
(n=1,604)\end{array}$ \\
\hline Age, years & $83.8 \pm 7.3$ & $80.0 \pm 6.9$ \\
\hline Female gender & $845(83.7 \%)$ & $1,092(68.1 \%)$ \\
\hline \multicolumn{3}{|l|}{ Prevalent comorbidity } \\
\hline Hypertension (ICD I10-I14) & $729(72.2 \%)$ & $1,244(77.6 \%)$ \\
\hline Chronic ischemic heart disease (ICD I20, I21, I25) & $391(38.7 \%)$ & $695(43.3 \%)$ \\
\hline Congestive heart failure (ICD I50) & $501(49.6 \%)$ & $666(41.5 \%)$ \\
\hline Previous cerebrovascular event (ICD G45, I60-I64, I69) & $348(34.4 \%)$ & $510(31.8 \%)$ \\
\hline Hyperlipidemia (ICD E78) & $326(32.3 \%)$ & $813(50.7 \%)$ \\
\hline \multicolumn{3}{|l|}{ Diabetic medication } \\
\hline None & $500(49.5 \%)$ & $666(41.5 \%)$ \\
\hline Insulin (ATC A10A) & $184(18.2 \%)$ & $224(14.0 \%)$ \\
\hline OADs (ATC A10B) & $245(24.3 \%)$ & $556(34.7 \%)$ \\
\hline Combination of OAD and insulin (ATC A10A + A10B) & $81(8.0 \%)$ & $158(9.9 \%)$ \\
\hline \multicolumn{3}{|l|}{ LoCD } \\
\hline No LoCD & $0(0 \%)$ & $903(56.3 \%)$ \\
\hline LoCD1 & $255(25.3 \%)$ & $326(20.3 \%)$ \\
\hline LoCD2 & $423(41.9 \%)$ & $259(16.2 \%)$ \\
\hline LoCD3 & $332(32.9 \%)$ & $116(7.2 \%)$ \\
\hline
\end{tabular}

Values are presented as mean \pm SD or $n(\%)$. LoCD, level of care dependency; OAD(s), oral antidiabetic $\operatorname{drug}(\mathrm{s})$.

being most pronounced regarding checks of blood glucose (65.2 vs. 84.4\%), cholesterol (23.7 vs. $42.5 \%$ ), and microalbumin status (3.9 vs. $14.8 \%$ ). Moreover, there was a trend toward less intense DRMEs in those with a higher LoCD, and institutionalized dementia patients in any LoCD tended to receive fewer DRMEs than community dwellers in the same LoCD (Table 2). However, owing to small sample sizes, these general trends were mostly not statistically significant.

Intra-individual changes in the context of nursing home placement revealed that after nursing home placement, the intensity of all medical examinations was lower than before (Table 3), in spite of the probability being significant only for HbA1c level, cholesterol level, and examinations of the ocular background.

\section{Costs of Diabetes Care}

Figure 2 displays the share of diabetes-related expenditures in total SHI expenditures as well as the corresponding monetary amount for community dwellers and nursing home residents in each LoCD. By trend, the costs of diabetes care decreased with increasing LoCD for both care settings, with LoCD-specific expenditures being continuously higher in the community setting. Moreover, the relevance of diabetes care (defined as the share of total SHI expenditures) declined in higher LoCD.

\section{Discussion}

To the best of our knowledge, this study is the first to compare delivery of DRMEs and diabetes-related expenditures in nursing home residents and community dwellers with dementia. 
Table 2. Diabetes-related medical examinations according to LoCD

\begin{tabular}{|c|c|c|c|c|c|}
\hline $\begin{array}{l}\text { Performed at least once } \\
\text { in } 2006\end{array}$ & LoCD & $\begin{array}{l}\text { Nursing home } \\
\text { residency }\end{array}$ & $\begin{array}{l}\text { Community- } \\
\text { living }\end{array}$ & $\begin{array}{l}\text { Odds } \\
\text { ratio }^{\text {a }}\end{array}$ & $p$ value \\
\hline \multirow[t]{4}{*}{ HbA1c level } & No LoCD & $0(0 \%)$ & $694(76.9 \%)$ & & \\
\hline & LoCD1 & $162(63.5 \%)$ & $229(70.3 \%)$ & 0.81 & 0.26 \\
\hline & LoCD2 & $230(54.4 \%)$ & $164(63.3 \%)$ & 0.77 & 0.15 \\
\hline & LoCD3 & $135(40.7 \%)$ & $49(42.2 \%)$ & 1.12 & 0.63 \\
\hline \multirow[t]{4}{*}{ Blood glucose level } & No LoCD & $0(0 \%)$ & 783 (86.7\%) & & \\
\hline & LoCD1 & $190(74.5 \%)$ & $274(84.1 \%)$ & 0.60 & 0.018 \\
\hline & LoCD2 & $274(64.8 \%)$ & $222(85.7 \%)$ & 0.31 & $<0.0001$ \\
\hline & LoCD3 & $194(58.4 \%)$ & 75 (64.7\%) & 0.84 & 0.45 \\
\hline \multirow[t]{4}{*}{ Creatinine level } & No LoCD & $0(0 \%)$ & $736(81.5 \%)$ & & \\
\hline & LoCD1 & $176(69.0 \%)$ & $246(75.5 \%)$ & 0.83 & 0.36 \\
\hline & LoCD2 & $256(60.5 \%)$ & $178(68.7 \%)$ & 0.81 & 0.25 \\
\hline & LoCD3 & 158 (47.6\%) & 59 (50.9\%) & 0.97 & 0.90 \\
\hline \multirow[t]{4}{*}{ Microalbumin level } & No LoCD & $0(0 \%)$ & $180(19.9 \%)$ & & \\
\hline & LoCD1 & $14(5.5 \%)$ & $40(12.3 \%)$ & 0.45 & 0.02 \\
\hline & LoCD2 & $16(3.8 \%)$ & $14(5.4 \%)$ & 0.86 & 0.72 \\
\hline & LoCD3 & $9(2.7 \%)$ & $4(3.5 \%)$ & 0.82 & 0.76 \\
\hline \multirow[t]{4}{*}{ Cholesterol level } & No LoCD & $0(0 \%)$ & 437 (48.4\%) & & \\
\hline & LoCD1 & 77 (30.2\%) & $132(40.5 \%)$ & 0.67 & 0.03 \\
\hline & LoCD 2 & 97 (22.9\%) & $90(34.8 \%)$ & 0.63 & 0.01 \\
\hline & LoCD 3 & 65 (19.6\%) & $23(19.8 \%)$ & 1.14 & 0.64 \\
\hline Examination of ocular & No LoCD & $0(0 \%)$ & 315 (34.9\%) & & \\
\hline \multirow[t]{3}{*}{ background } & LoCD1 & 47 (18.4\%) & $63(19.3 \%)$ & 0.95 & 0.80 \\
\hline & LoCD2 & $43(10.2 \%)$ & $31(12.0 \%)$ & 0.88 & 0.62 \\
\hline & LoCD3 & $9(2.7 \%)$ & $5(4.3 \%)$ & 0.87 & 0.82 \\
\hline
\end{tabular}

Values are presented as $n(\%) .{ }^{\text {a }}$ Adjusted for age, gender, comorbidity, and type of diabetic medication. HbA1c, glycated hemoglobin; LoCD, level of care dependency.

Table 3. Diabetes-related medical examinations of individuals with dementia and diabetes 365 days before and after nursing home placement

\begin{tabular}{lccc}
\hline Performed at least once & $\begin{array}{l}\text { Before nursing home } \\
\text { placement }\end{array}$ & $\begin{array}{l}\text { After nursing home } \\
\text { placement }\end{array}$ & $p$ value \\
\hline HbA1c level & $102(68.5 \%)$ & $86(57.7 \%)$ & 0.02 \\
Blood glucose level & $117(78.5 \%)$ & $108(72.5 \%)$ & 0.20 \\
Creatinine level & $110(73.8 \%)$ & $104(69.8 \%)$ & 0.42 \\
Microalbumin level & $12(8.0 \%)$ & $8(5.3 \%)$ & 0.35 \\
Cholesterol level & $55(36.9 \%)$ & $34(22.8 \%)$ & 0.003 \\
Examination of ocular background & $41(27.5 \%)$ & $26(17.4 \%)$ & 0.02 \\
\hline
\end{tabular}

Values are presented as $n(\%)$. Adjusted for age, gender, comorbidity, type of diabetic medication, and level of care dependency. HbA1c, glycated hemoglobin. 


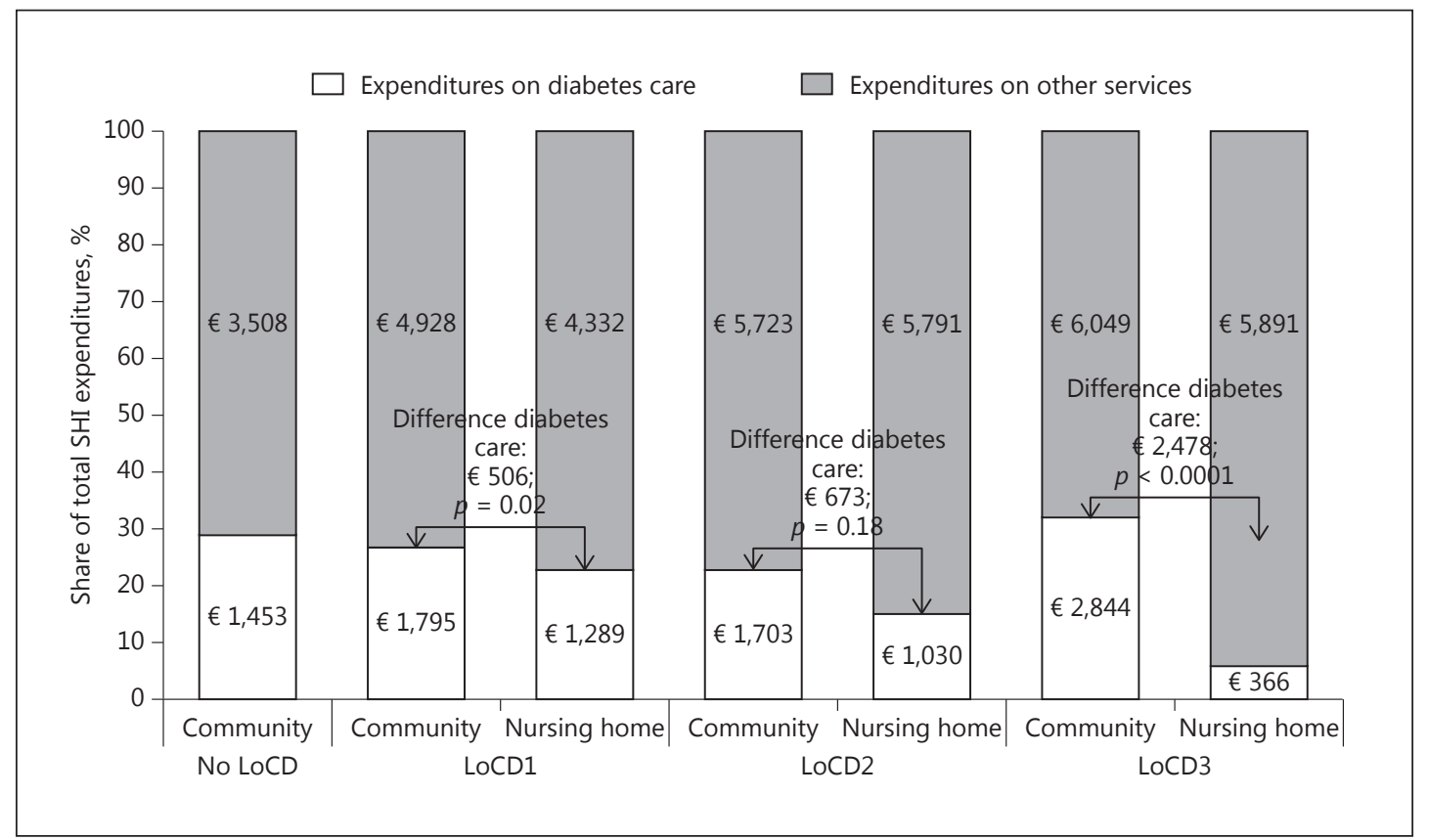

Fig. 2. Share of diabetes-related expenditures in total SHI expenditures stratified by level of care dependency (LoCD). SHI, Statutory Health Insurance.

The analyses indicate that DRMEs are not provided to the extent recommended in guidelines and expert recommendations [22,30,31], with the shortfall being more pronounced in nursing homes. This matches the finding of Fahey et al. [15] and our own longitudinal analysis, but contradicts the results of Quinn et al. [18].

The costs of diabetes care and their share in all-cause SHI expenditures decrease with increasing LoCD. Decreasing (I)ADL capacities can be seen as an indicator of progressing dementia [32]. Hence, our results suggest that cognitive decline and reduced self-care capacity go along with reduced emphasis on diabetes care. However, the control of blood parameters relevant for diabetes management should remain at a high level in more advanced dementia as well, as metabolic imbalances and hyperglycemic episodes contribute to the progression of cognitive decline [16,33]. Moreover, less close-meshed controls increase the risk of diabetes-related complications and sequelae, which are very costly to treat. Own unpublished analyses of the study sample indeed documented that hypoglycemic episodes and peripheral vascular complications tended to be more frequent in nursing home residents with dementia and diabetes.

In general, diabetes care was more costly when provided to community dwellers. Here, the main reason are SHI-paid services of home health care that cover, e.g., professional support for insulin injections. For nursing home residents, these tasks fall into the scope of LTCI. This segregated financing might also hamper a comprehensive approach toward diabetes management.

When interpreting the results of our comprehensive analyses, the strengths and weaknesses of claims data-based research need to be kept in mind [34].

First, clinical parameters are not available, rendering an unambiguous assessment of disease severity impossible. It seems justified to use diabetes-specific medication as a proxy for diabetes severity [35] and LoCD, which reflect (I)ADL impairment, as a proxy for dementia severity [32]. Therefore, stratifying the analyses by LoCD provides some indication as to how 
the intensity of diabetes care develops in the course of dementia progression, whereas the adjustment for type of diabetic medication possibly accounts for differences related to diabetes severity.

A further limitation is the restriction to service utilization billable within the German SHI system. Essential DRMEs (e.g., the examination of feet to prevent ulcers) do not have their own code but are subsumed under a basic flat rate. Thus, their provision cannot be assessed, and potential differences between the community and the institutional setting remain undetected. Moreover, services organized individually and paid for out-of-pocket are disregarded. Hence, our results tend to underestimate the "true" intensity of service provision and the costs of diabetes care.

On the other hand, claims data by and large exclude selection bias, as they include all insurants irrespective of residential setting, health status, and sociocultural background. Dementia patients with diabetes represent a particularly frail, multimorbid clientele with very limited capacities of discernment and, hence, meet almost all well-established exclusion criteria for primary data-based research designs. Thus, our approach might be more promising than a study based on primary patient data.

In this regard, an additional advantage is avoiding recall bias. All health care services used are documented directly and do not need to be assessed in cooperation with the patient. Our research focuses on a population with limited cognitive abilities, where the risk of inaccurate reminiscence is extremely high, rendering misreporting quite likely. Cost information, too, is directly reported in the dataset. Hence, inaccuracies owing to the assignment of unit costs to the distinct utilization figures [36] is avoided, and the entire range of service-specific expenditures is considered.

The analyzed parameters reflect the structure and processes of diabetes care but, as they cannot be matched with clinical data, conclusions on outcome quality are difficult, and so is judging the medical appropriateness of the observed service provision patterns.

Different framework conditions in the distinct settings might also contribute to differences in the intensity of DRMEs. In general, nursing home residents have a more structured daily routine. Therefore, regular checks of blood parameters might be less urgent because a good baseline adjustment seems more likely than in a by and large individually managed diabetes patient in the community. However, this assumption contradicts a recent analysis that found no difference in HbA1c values for elderly patients in various care settings [17].

In conclusion, our analyses indicate DRMEs to be at a reduced level in nursing home residents with dementia, particularly in those with a higher LoCD. Contrary to the initial hypothesis, the high degree of professionalization in nursing homes does not have a substantially positive impact on diabetes management. This suggests particular need for systematic integration of medical specialists and closer cooperation between physicians and trained nursing staff. Here, making all individuals involved in the care process aware of the specific challenges of combined dementia and diabetes care [37] is an indispensable precondition.

\section{Acknowledgments}

This work was supported by a grant from the German Alzheimer Association. A contract between the sponsors and academic researchers ensures that the latter have full scientific responsibility and the right to publish the results. The authors thank the AOK Bavaria SHI Fund for providing the data for this study. Moreover, they are grateful for the help of Martin Rehm with graphic and table editing and for the support of Anitha Tulashi Raman in formatting the manuscript. Finally, the authors greatly appreciate the comments and remarks of their anonymous referees, which significantly improved the clarity and precision of this paper. 


\section{Disclosure Statement}

None of the authors has any conflicting interests to declare.

\section{References}

1 Bickel H: Dementia in advanced age: estimating incidence and health care costs (in German). Z Gerontol Geriatr 2001;34:108-115.

12 Ziegler U, Doblhammer G: Prevalence and incidence of dementia in Germany - a study based on data from the public sick funds in 2002 (in German). Gesundheitswesen 2009;71:281-290.

3 Heidemann C, Du Y, Scheidt-Nave C: Diabetes mellitus in Deutschland. Berlin, Robert Koch Institute (editor), 2011 (last accessed February 7, 2017).

4 Hauner H, Köster I, Schubert I: Prevalence of diabetes mellitus and quality of care in Hesse, Germany, 19982004. Dtsch Arztebl Int 2007;104(41):A-2799.

5 Löppönen MK, Isoaho RE, Raiha IJ, Vahlberg TJ, Loikas SM, Takala TI, Puolijoki H, Irjala KM, Kivela SL: Undiagnosed diseases in patients with dementia - a potential target group for intervention. Dement Geriatr Cogn Disord 2004;18:321-329.

6 Zekry D, Herrmann FR, Grandjean R, Meynet MP, Michel JP, Gold G, Krause KH: Demented versus non-demented very old inpatients: the same comorbidities but poorer functional and nutritional status. Age Ageing 2008;37: 83-89.

7 Phelan EA, Borson S, Grothaus L, Balch S, Larson EB: Association of incident dementia with hospitalizations. JAMA 2012;307:165-172.

8 Cheng G, Huang C, Deng H, Wang H: Diabetes as a risk factor for dementia and mild cognitive impairment: a meta-analysis of longitudinal studies. Intern Med J 2012;42:484-491.

-9 Munshi M, Grande L, Hayes M, Ayres D, Suhl E, Capelson R, Lin S, Milberg W, Weinger K: Cognitive dysfunction is associated with poor diabetes control in older adults. Diabetes Care 2006;29:1794-1799.

10 Sinclair AJ, Girling AJ, Bayer AJ: Cognitive dysfunction in older subjects with diabetes mellitus: impact on diabetes self-management and use of care services. All Wales Research into Elderly (AWARE) Study. Diabetes Res Clin Pract 2000;50:203-212.

11 Bayer AJ, Johnston J, Sinclair AJ: Impact of dementia on diabetic care in the aged. J R Soc Med 1994;87:619-621.

12 Thorpe CT, Thorpe JM, Kind AJ, Bartels CM, Everett CM, Smith MA: Receipt of monitoring of diabetes mellitus in older adults with comorbid dementia. J Am Geriatr Soc 2012;60:644-651.

13 Muther J, Abholz HH, Wiese B, Fuchs A, Wollny A, Pentzek M: Are patients with dementia treated as well as patients without dementia for hypertension, diabetes, and hyperlipidaemia? Br J Gen Pract 2010;60:671-674.

14 Jones LE, Clarke W, Carney CP: Receipt of diabetes services by insured adults with and without claims for mental disorders. Med Care 2004;42:1167-1175.

15 Fahey T, Montgomery AA, Barnes J, Protheroe J: Quality of care for elderly residents in nursing homes and elderly people living at home: controlled observational study. BMJ 2003;326:580.

16 Zeyfang A, Dippel FW, Bahrmann A, Bahr R, Feucht I, Hamann O, Hodeck K: Health services research in insulintreated geriatric patients in Germany in nursing homes or ambulatory care: results of the LIVE-GERI-study. Diabetol Stoffwechsel 2010;5:293-300.

17 Bahrmann A, Abel A, Specht-Leible N, Worz E, Holscher E, Zieschang T, Oster P, Zeyfang A: Treatment quality in geriatric patients with diabetes mellitus in various home environments (in German). Z Gerontol Geriatr 2010;43:386-392.

18 Quinn CC, Gruber-Baldini AL, Port CL, May C, Stuart B, Hebel JR, Zimmerman S, Burton L, Zuckerman IH, Fahlman C, Magaziner J: The role of nursing home admission and dementia status on care for diabetes mellitus. J Am Geriatr Soc 2009;57:1628-1633.

19 Schwarzkopf L, Menn P, Leidl R, Wunder S, Mehlig H, Marx P, Graessel E, Holle R: Excess costs of dementia disorders and the role of age and gender - an analysis of German health and long-term care insurance claims data. BMC Health Serv Res 2012;12:165.

20 Rothgang H: Social insurance for long-term care: an evaluation of the German model. Soc Policy Adm 2010;44: 436-460.

21 Schunk M, Estes C: Is German long-term care insurance a model for the United States? Int J Health Serv 2001;31:617-634.

22 Hader C, Beischer W, Braun A, Dreyer M, Friedl A, Füsgen I, Gastes U, Grüneklee D, Hauner H, Köbberling J: Diagnostik, Therapie und Verlaufskontrolle des Diabetes mellitus im Alter. Diabetes Stoffwechsel 2004;13:S31S56.

23 Akobundu E, Ju J, Blatt L, Mullins CD: Cost-of-illness studies: a review of current methods. Pharmacoeconomics 2006;24:869-890.

24 Du Y, Heidemann C, Gosswald A, Schmich P, Scheidt-Nave C: Prevalence and comorbidity of diabetes mellitus among non-institutionalized older adults in Germany - results of the national telephone health interview survey “German Health Update (GEDA)” 2009. BMC Public Health 2013;13:166. 
25 Schäfer I, von Leitner EC, Schön G, Koller D, Hansen H, Kolonko T, Kaduszkiewicz H, Wegscheider K, Glaeske $\mathrm{G}$, van den Bussche H: Multimorbidity patterns in the elderly: a new approach of disease clustering identifies complex interrelations between chronic conditions. PLoS One 2010;5:e15941.

26 Dean CB, Nielsen JD: Generalized linear mixed models: a review and some extensions. Lifetime Data Anal 2007;13:497-512.

27 Manning WG, Basu A, Mullahy J: Generalized modeling approaches to risk adjustment of skewed outcomes data. J Health Econ 2005;24:465-488.

28 Kilian R, Matschinger H, Loeffler W, Roick C, Angermeyer MC: A comparison of methods to handle skew distributed cost variables in the analysis of the resource consumption in schizophrenia treatment. J Ment Health Policy Econ 2002;5:21-31.

29 Glick HA, Doshi JA, Sonnad SS, Polsky D: Economic Evaluation in Clinical Trials. Oxford, Oxford University Press, 2007.

-30 Bahrmann A, Bahrmann P, Kubiak T, Kopf D, Oster P, Sieber CC, Daniel WG: Diabetes and dementia (in German). Z Gerontol Geriatr 2012;45:17-22.

31 Zeyfang A, Bahrmann A, Wernecke J: Diabetes mellitus im Alter. Diabetol Stoffwechsel 2011;6:170-175.

-32 Mauskopf J, Racketa J, Sherrill E: Alzheimer's disease: the strength of association of costs with different measures of disease severity. J Nutr Health Aging 2010;14:655-663.

-33 Bahrmann A, Worz E, Specht-Leible N, Oster P, Bahrmann P: Diabetes care and incidence of severe hypoglycemia in nursing home facilities and nursing services: the Heidelberg Diabetes Study (in German). Z Gerontol Geriatr 2015;48:246-254.

34 Schubert I, Köster I, Küpper-Nybelen J, Ihle P: Versorgungsforschung mit GKV-Routinedaten. Bundesgesundheitsblatt Gesundheitsforschung Gesundheitsschutz 2008;51:1095-1105.

35 Schunk M, Reitmeir P, Schipf S, Volzke H, Meisinger C, Ladwig KH, Kluttig A, Greiser KH, Berger K, Muller G, Ellert U, Neuhauser H, Tamayo T, Rathmann W, Holle R: Health-related quality of life in women and men with type 2 diabetes: a comparison across treatment groups. J Diabetes Complications 2015;29:203-211.

36 Bock JO, Brettschneider C, Seidl H, Bowles D, Holle R, Greiner W, Konig HH: Calculation of standardised unit costs from a societal perspective for health economic evaluation (in German). Gesundheitswesen 2015;77: 53-61.

-37 Sinclair AJ, Hillson R, Bayer AJ: Diabetes and dementia in older people: a best clinical practice statement by a multidisciplinary National Expert Working Group. Diabet Med 2014;31:1024-1031. 